\title{
Efficiency of an Active Rehabilitation Intervention in a Slow-to-Recover Paediatric Population following Mild Traumatic Brain Injury: A Pilot Study
}

\author{
Sarah Imhoff, ${ }^{1,2,3}$ Philippe Fait, ${ }^{1,2,3,4}$ Frédérike Carrier-Toutant, ${ }^{3,5}$ and Geneviève Boulard ${ }^{3,5}$ \\ ${ }^{1}$ Department of Human Kinetics, Université du Québec à Trois-Rivières (UQTR), 3351 Boulevard des Forges, \\ Trois-Rivières, QC, Canada G9A 5 H7 \\ ${ }^{2}$ Research Group on Neuromusculoskeletal Dysfunctions (GRAN), UQTR, 3351 Boulevard des Forges, \\ Trois-Rivières, QC, Canada G9A 5H7 \\ ${ }^{3}$ Cortex Médecine et Réadaptation Concussion Clinic, 205-1035 Avenue Wilfrid-Pelletier, Québec City, QC, Canada G1W 0C5 \\ ${ }^{4}$ Research Center in Neuropsychology and Cognition (CERNEC), Université de Montréal, 90 rue Vincent d'Indy, \\ Montréal, QC, Canada H2V $2 S 9$ \\ ${ }^{5}$ Clinique Neuropsychologique, 206-1379 Chemin Ste-Foy, Québec City, QC, Canada G1S 2N2
}

Correspondence should be addressed to Philippe Fait; philippe.fait@uqtr.ca

Received 1 June 2016; Revised 12 September 2016; Accepted 23 October 2016

Academic Editor: S. John Sullivan

Copyright (c) 2016 Sarah Imhoff et al. This is an open access article distributed under the Creative Commons Attribution License, which permits unrestricted use, distribution, and reproduction in any medium, provided the original work is properly cited.

\begin{abstract}
Objective. The aim of this study was to identify whether the addition of an individualised Active Rehabilitation Intervention to standard care influences recovery of young patients who are slow-to-recover following a mTBI. Methods. Fifteen participants aged $15 \pm 2$ years received standard care and an individualised Active Rehabilitation Intervention which included (1) low-to high-intensity aerobic training; (2) sport-specific coordination exercises; and (3) therapeutic balance exercises. The following criteria were used to measure the resolution of signs and symptoms of mTBI: (1) absence of postconcussion symptoms for more than 7 consecutive days; (2) cognitive function corresponding to normative data; and (3) absence of deficits in coordination and balance. Results. The Active Rehabilitation Intervention lasted $49 \pm 17$ days. The duration of the intervention was correlated with self-reported participation $(\bar{x}=84.64 \pm 19.63 \%, r=-0.792, p<0.001)$. The average postconcussion symptom inventory (PCSI) score went from a total of $36.85 \pm 23.21$ points to $4.31 \pm 5.04$ points after the intervention $(Z=-3.18, p=0.001)$. Conclusion. A progressive submaximal Active Rehabilitation Intervention may represent an important asset in the recovery of young patients who are slow-to-recover following a mTBI.
\end{abstract}

\section{Introduction}

Mild traumatic brain injury (mTBI), or concussion, is an acute neurological disorder induced after a direct or indirect mechanical impact to the head (acceleration, deceleration, rotational force, etc.) [1]. MTBI is the most common type of brain injury, and it represents a major health problem in children and adolescents, as they are highly represented in sport-related head injury [2-5]. The annual incidence of mTBI in Canadians is estimated at 600 per 100,000 inhabitants $[6,7]$. Although recovery following mTBI is usually a short-lived process (7-10 days), physical, cognitive, and emotional symptoms and sleep disorder may persist beyond the expected recovery period of one to three months in $10-30 \%$ of mTBI cases in youth [8-11]. Postconcussion syndrome (PCS) refers to persisting symptoms for more than 1 month following a mTBI, including headache, nausea, dizziness, fatigue, vision impairment, sensitivity to noise and/or light, balance impairment, difficulty concentrating, memory impairment, drowsiness, anxiety, irritability, and feeling "in a fog" (WHO ICD-10). Barlow et al. [8] found that $58.5 \%$ of children aged from 0 to 18 years who sustained a mTBI were still symptomatic 1 month following the incident. Whereas children and adolescents presenting postconcussion symptoms beyond 1 month following a mTBI are considered slow-to-recover, there is a need to develop feasible and 
valid interventions to improve recovery in the paediatric population who sustained a mTBI.

Little is known about the treatment of mTBI, especially when postconcussion symptoms persist beyond the normal expected period of convalescence. Up to now, rest has been considered as "the gold standard" after sustaining a mTBI. Thus, consensus statements either recommend that athletes should rest until they are asymptomatic before introducing physical activity [12-14] or do not state on how and when physical activity should be introduced when symptoms persist beyond the expected recovery period $[1$, 15]. It has been suggested that aerobic exercise could restore cerebrovascular function and autonomic balance following mTBI [16-24]. Recent reviews of the literature support the benefits of exercise as an active rehabilitation treatment when postconcussion symptoms persist beyond the expected recovery period after injury $[20,21,25,26]$. Indeed, it has been postulated that the introduction of physical activity may have a positive impact on the chronic symptoms following mTBI [17, 24, 27-42]. Preliminary evidence demonstrated that exercise, when used as a treatment, reduces reported symptoms in adults $[17,18,22,43,44]$ and in youth who are slow-to-recover after mTBI $[9,35,45]$. For the sake of improving knowledge about the care of youth with atypical recovery following a mTBI, we studied the effectiveness of the integration of an Active Rehabilitation Intervention coupled with standard care while participants were still experiencing postconcussion symptoms at rest. Considering the lack of available scientific literature on active rehabilitation, we adapted the paediatric active rehabilitation program described by Gagnon et al. [9]. Our Active Rehabilitation Intervention differed in training frequency (3 times a week versus daily) and intensity reached by the end of the treatment.

The aim of this study was to identify whether the addition of an individualised Active Rehabilitation Intervention to standard care influences recovery of young patients who are slow-to-recover following an mTBI and still symptomatic at rest.

\section{Methods}

2.1. Participants. Eighteen participants aged from 10 to 17 years who complained of postconcussion symptoms for more than 4 weeks following a mTBI were referred to the Active Rehabilitation Intervention study through the Cortex Medicine and Rehabilitation Concussion Clinic (Québec city, $Q c$, Canada). Participants received an interdisciplinary intervention consisting of rest, general education, school adaptations, and putting a halt to participation in physical activities, as proposed by the Zurich Consensus [1]. The study was explained to the families by a registered neuropsychologist during an initial 1-hour meeting in which the interdisciplinary approach was presented and the patient interview was conducted. Written parental consent and participant assent were obtained if both indicated an interest in the study. The research project was approved by the Ethics Review Board of Université du Québec à Trois-Rivières (UQTR).
2.2. Study Design. Participants underwent a full assessment looking for symptoms and neurological, balance, and coordination impairments before and after the Active Rehabilitation Intervention. The initial evaluation was conducted $49 \pm 17$ days after mTBI. A standardized mTBI history questionnaire was administered by a trained neuropsychologist to obtain detailed information about the mTBI history, including the date of the injury, the mechanism of injury, the clinical symptoms (loss of consciousness, confusion, and amnesia), and the number of autoreported previous mTBI. Participation in the program and self-report symptoms were assessed during a weekly follow-up phone call. Final evaluation was conducted when the participants reported being asymptomatic for a minimum of seven days. The following criteria were used to determine the resolution of signs and symptoms of mTBI: (1) absence of postconcussive symptoms for more than seven consecutive days; (2) cognitive function corresponding to normative data when assessed by a neuropsychologist; and (3) absence of deficits in coordination and balance.

2.3. Active Rehabilitation Intervention. Since participants were still presenting postconcussion symptoms at rest, they could not perform the standard 6-step gradual return to physical activities as proposed by the 2013 Zurich Consensus [1]. They were asked to perform a personalized homebased active rehabilitation program which consisted of (1) progressive submaximal low- to high-intensity (based on perceived exertion) aerobic training for up to $20 \mathrm{~min}$, (2) low-intensity sport-specific coordination exercises for up to $10 \mathrm{~min}$, and (3) therapeutic balance exercises (Figure 1). The active rehabilitation program was initially performed in a clinic under the supervision of a licensed kinesiologist. Participants were asked to perform the active rehabilitation program 3 times a week at home, at school, at a sport facility, or at the clinic. The individualised home-based program was inspired from the Montréal Children's Hospital Trauma Centre Concussion Clinic/Mild Traumatic Brain Injury Program $(\mathrm{MCH})[9,45]$, but differed in the frequency of participation (3 times a week in the present study versus daily at the $\mathrm{MCH}$ ) in order to facilitate treatment compliance and minimize the impact on participants' daily life. This also enabled a greater difference in daily participation in exercises, allowing better monitoring of symptoms that may have been created through exercise since symptoms can be compared between a day without physical activity and the day where the rehabilitation program was conducted. It allowed assurances that the intervention was not harmful to the participant. This training schedule also enables a day of rest between high-intensity training periods. This allowed the exercise session to be more difficult without risking overtiredness for the participant and creating an increase in symptoms. Our Active Rehabilitation Intervention also differed in the intensity and duration of aerobic exercise reached by the end of the program, which was similar to those of rehabilitation programs conducted in adults. The intensity reached by the end of the program was therefore closer to the one usually performed in organized sports. This may promote a better transition to the sport practised by the participant and could enable a more complete rehabilitation. 


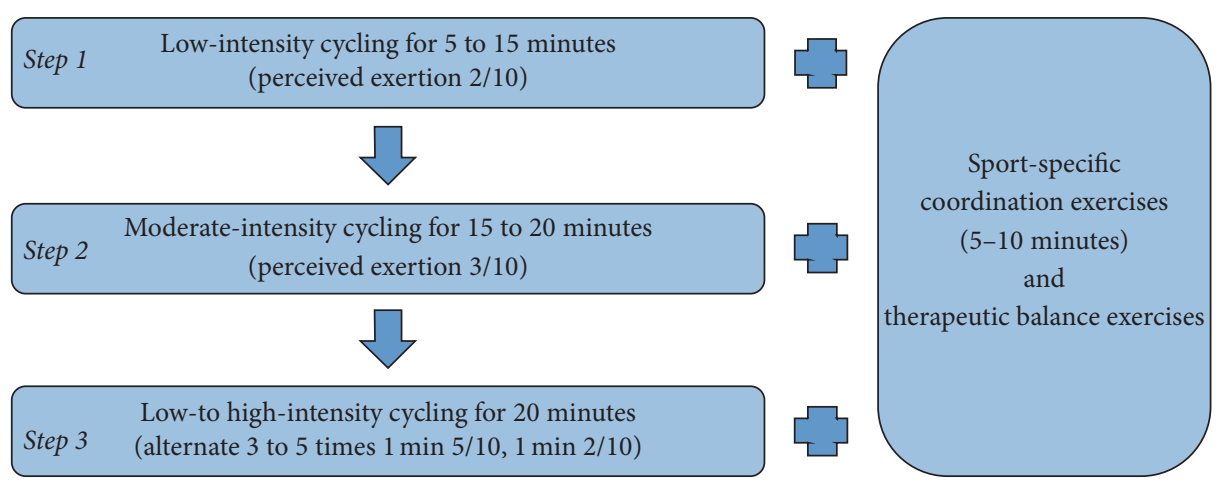

FIGURE 1: Active Rehabilitation Intervention.

Patients were requested to limit the duration and intensity of exercises to those prescribed according to their clinical evaluation. They were asked to perform their program even if they were symptomatic at rest but had to stop the exercise if any of the current symptoms increased by 1 point on a symptom intensity scale from 0 to 10 points or at any onset of a new symptom. Participants had to regress one stage in the program if symptoms were exacerbated after exercise participation.

2.3.1. Aerobic Training. Participants were asked to use an upright cycling ergometer to perform individualised progressive aerobic training program. Because of difficult access to a cycling ergometer, participant \#7 used an elliptic. The level of perceived exertion was monitored using the 10-point Borg category-ratio scale (CR10), where effort is rated from none (0) to maximal (10) [46]. This scale was incorporated into the home program in order to help participants monitor exercise intensity. First, participants were asked to perform a symptom-dependent low-intensity supervised aerobic training session aiming to determine the volume at which they would initiate the aerobic training progression (between 5 and $15 \mathrm{~min}$ ). In this protocol, participants evolved through three progressive stages in terms of volume and intensity, until symptom free: (1) $5 \mathrm{~min}$ progression every two sessions, from 5 to $15 \mathrm{~min}$ of low-intensity aerobic activity (perceived exertion of 2/10), (2) $5 \mathrm{~min}$ progression every two sessions, from 15 to 20 minutes of moderate-intensity aerobic activity (perceived exertion of 3/10), and (3) 5 min of low-intensity aerobic activity (perceived exertion of $2 / 10$ ), followed by three-to-five low- to high-intensity intervals (alternate $1 \mathrm{~min}$ at high-intensity (perceived exertion of 5/10) and $1 \mathrm{~min}$ at low-intensity aerobic activity (perceived exertion of 2/10)), followed by $5 \mathrm{~min}$ low-intensity aerobic activity (perceived exertion of 2/10). The onset or increase of symptoms led to immediate termination of exercise for a minimum of 24 hours. Patients were asked to return to the previous stage if any of the symptoms increased by 1 point on a 10-point symptoms intensity scale during or after exercise. They had to progress through stages if they successfully completed a stage twice in a row. They were instructed not to exercise for two consecutive days.
2.3.2. Sport-Specific Coordination Exercises. Participants had to perform low-intensity (2/10) sport-specific coordination skills (shooting drills, dribbling drills, agility, etc.) for 5 to 10 min after every session of aerobic training. The activity had to be stopped if it generated any symptoms.

2.3.3. Therapeutic Balance Exercises. Participants were asked to perform three 30 -seconds repetition of three therapeutic exercises consisting in balance exercises (standing on one foot with eyes closed, feet in tandem on an unstable surface, etc.) (Figure 3).

The home program included all three components of the Active Rehabilitation Intervention program and was provided to the families on paper. Progression was monitored through a weekly follow-up phone call. The participants and parents were asked to contact the study coordinator for any questions or if symptoms worsened or resolved. Follow-up was conducted until the participant reported being symptomfree for at least 7 days.

2.4. Participation in the Active Rehabilitation Intervention. Participation in the Active Rehabilitation Intervention was monitored through weekly follow-up phone calls and was determined by comparing a participant's report of exercises sessions performed with exercise sessions prescription (\%). Correlation between the duration of the intervention and self-reported participation was calculated to evaluate the dose-response relationship.

\subsection{Signs and Symptoms Assessment}

2.5.1. Symptoms Assessment. Current postconcussion symptoms and preinjury symptoms severity were assessed by the Postconcussive Symptom Inventory scale (PCSI) [42]. The PCSI is a validated questionnaire of 21 items rated from 0 to 6 $(0=$ absence of symptom and $6=$ severe problem $)$ for youth of 13 to 18 years old who sustained a mTBI, where item 21 is a self-reported abnormality score rated from " 0 " indicating "No Difference" to "4" indicating "Very Different." The first 20 items' scores were added in order to create the PCSI score (0-120 points). The 18-item PCSI questionnaire form was used for participants under 13 years of age. Parents were asked to complete the PCSI parent version to rate their children's perceived symptom severity. Pre- and postintervention PCSI 
scores and self-reported abnormality scores were compared for each participant and parent and between the participant and their parent. The PCSI score results for participants \#3 and \#11 have not been considered in the statistical analysis due to the use of incompatible versions of the questionnaires.

2.5.2. Neuropsychological Assessment. A battery of neuropsychological tests was used to assess multiple aspects of cognitive functioning, including verbal memory (Rey Auditory Verbal Learning Test (RAVLT) [47]), verbal fluency (DelisKaplan executive function system (D-KEFS) [48]), working memory (Digit Span from the Weschler Adult Intelligent Scale (WAIS-IV) [49] or from the Weschler Intelligence Scale for Children (WISC-IV) [50]), information processing (Symbol Digit Modality Test (SDMT) [51]), and attention processes (Continuous Performance Test II (CPT-II) [52]). The tests were selected to evaluate the most affected cognitive functions following an mTBI as reported in the literature [53, 54]. This neuropsychological test battery was administered by a trained neuropsychologist. The test administration was standardized and uniform for all participants.

A psychological inventory (State-Trait Anxiety Inventory (STAI) [55]) was also administered to the participants' parents to measure their anxiety about their child's condition and their anxiety level as a personal characteristic [55].

2.5.3. Coordination and Balance. Coordination and balance were assessed by subtests from the Sport Concussion Assessment Tool v3 (SCAT3) Balance examination tests and coordination examination [1] through the Modified Balance Error Scoring System (BESS) testing, the tandem gait and the Finger-to-nose task. Participants performed the Modified Clinical Test of Sensory Interaction on Balance (m-CTSIB) [56], which measures static postural sway, and the Limit of Stability test (LOS), which measures dynamic postural control within a normalized sway envelope on a Biodex Biosway $^{\mathrm{TM}}$ force platform (Biodex Medical Systems, Inc. Shirley, NY, USA) [57]. Finally, balance and coordination were also assessed by the Bruininks-Oseretsky Test of Motor Proficiency 2nd Edition (BOT-2) subtests of bilateral coordination, balance, and upper-limb coordination [58].

2.6. Statistical Analysis. Spearman correlation between the duration of the intervention and self-reported participation in the Active Rehabilitation Intervention and between Active Rehabilitation Intervention duration and time post mTBI preintervention were calculated. The Wilcoxon non parametric test for related samples was conducted on every other outcome measures. Outcome measures statistical analyses were conducted with the Statistical Package for the Social Sciences (SPSS) version 22 (SPSS. Inc., Chicago, Illinois, USA). BOT-2 subtests total point scores were converted to derived scores in order to have uniform meaning between subtests and participants. Normalized age and sex scale scores were used for statistical analysis.

\section{Results}

All participants were previously engaged in organized recreational to high performance sport groups for $6 \pm 4$ hours per week. Most sustained a sport-related mTBI in their principal competitive activity $(n=14)$ or in another recreational activity $(n=2)$. Two participants sustained a motor vehiclerelated incident. From the previous 18 participants screened, 15 children and adolescents ( 9 females) aged $15.00 \pm 1.69$ years were included in this study. Three participants were excluded from the data analysis for the following reasons: one participant was not able to complete the final assessment because he suffered from a fractured toe and therefore decided to quit the rehabilitation program and two other participants returned to their sport without the consent of their treating clinicians, although they were still experiencing postconcussion symptoms. Participant characteristics are presented in Table 1. All participants had a normal academic progress and reported no cognitive, behavioural, neurological, or musculoskeletal impairments. Participant \#4 was treated with carbamazepine (Mylan-Carbamazepine CR) for epilepsy. Participant \#6 was diagnosed with influenza during the study and had flu symptoms for 10 days, after being asymptomatic for five days. Participant \#7 suffered from iron deficiency anaemia and anxiety disorder, had a history of migraines and was treated with iron supplements, almotriptan (Axert ${ }^{\circledR}$ ), and amitriptyline $\left(\right.$ Elavil $\left.^{\circledR}\right)$. No participants had sustained an mTBI in the previous 6 months before data collection. Seven participants reported amnesia of the event, three had lost consciousness, and five had sought medical attention at the emergency department. Participants \#3 and \#12 had an impact to the head during the study without convincing signs of mTBI. Screening and treatment for associated conditions of cervical ( $n=13)$, oculomotor $(n=10)$, vestibular $(n=5)$, and temporomandibular $(n=1)$ dysfunctions were conducted by a registered physiotherapist.

3.1. Intervention Duration before Recovery. Participants were initially evaluated at $48 \pm 88$ days after mTBI. The intervention lasted $49 \pm 17$ days before recovery was attained. The final evaluation was conducted after $9 \pm 2$ days without symptoms (Table 1). Spearman correlation revealed no correlation between the Active Rehabilitation Intervention duration and the duration of postconcussion symptoms before the intervention $(r=-0.120, p=0.671)$.

3.2. Participation in the Active Rehabilitation Intervention. Participants completed on average $85 \pm 20 \%$ of the Active Rehabilitation Intervention sessions prescribed. Duration of the intervention was correlated with self-reported participation score $(r=-0.796, p \leq 0.001)$ (Figure 2). Three participants did the Active Rehabilitation Intervention program 3 to 4 times a week (every two days) which explained participation score higher than $100 \%$.

3.3. Symptoms. Symptom frequency and severity decreased significantly after the intervention (see Table 2). Before the intervention, the participants reported an average of $8.9 \pm$ 2.1 symptoms on the PCSI. The number of self-reported symptoms decreased significantly to $1.8 \pm 1.4$ following the intervention $(Z=-3.933, p \leq 0.001)$. The most frequently symptoms from the pretest were fatigue $(n=13)$, difficulty concentrating $(n=12)$, headache $(n=11)$, and answering 


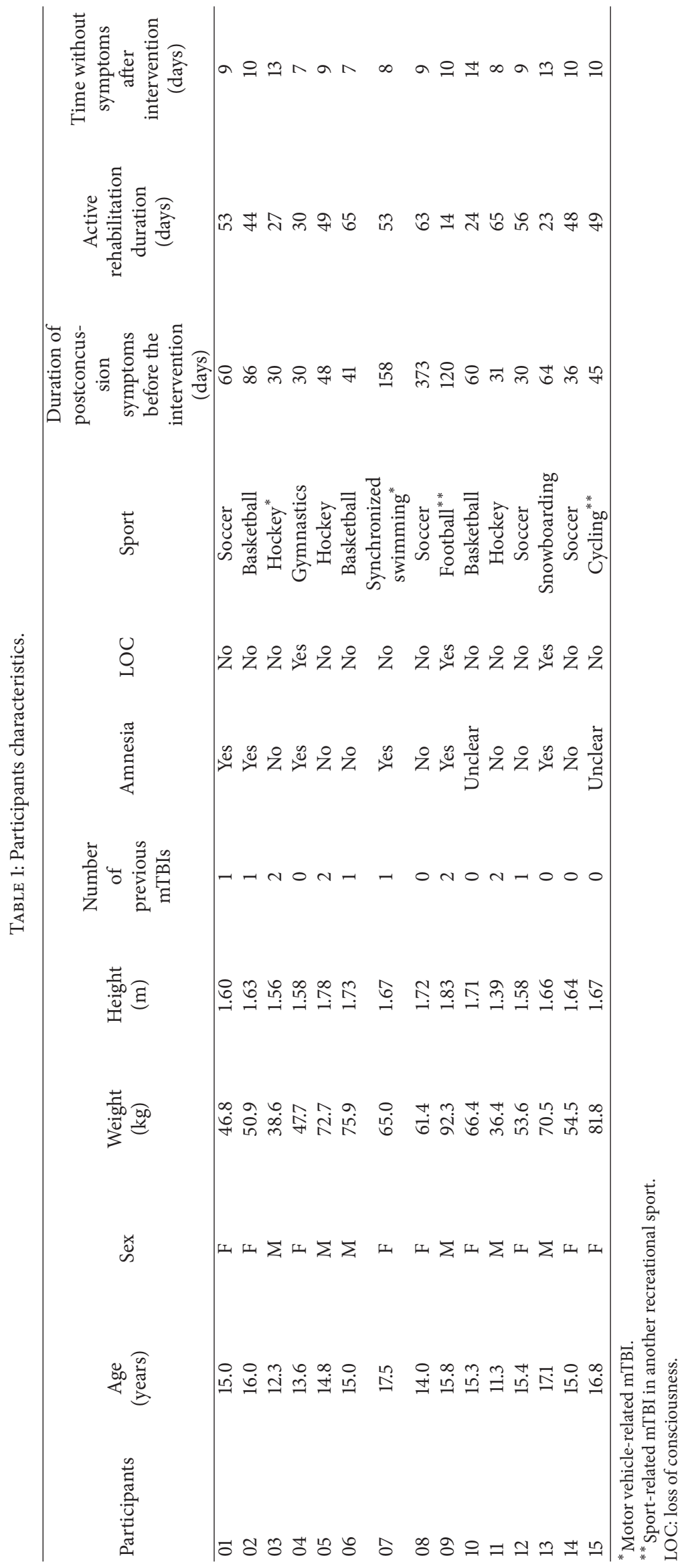


TABLE 2: Participants' postconcussion symptom inventory results.

\begin{tabular}{|c|c|c|c|c|}
\hline & Before intervention & After intervention & $Z$ & $p$ \\
\hline PCSI score (sum of 20 items) ${ }^{*}$ & $36.9 \pm 23.2$ & $4.3 \pm 5.0$ & $-3.180^{b}$ & 0.001 \\
\hline Self-reported abnormality score* & $2.0 \pm 3.3$ & $0.2 \pm 0.4$ & $-2.877^{\mathrm{b}}$ & 0.004 \\
\hline
\end{tabular}

${ }^{*}$ Significant statistical difference.

${ }^{\mathrm{b}}$ Based on positive ranks.

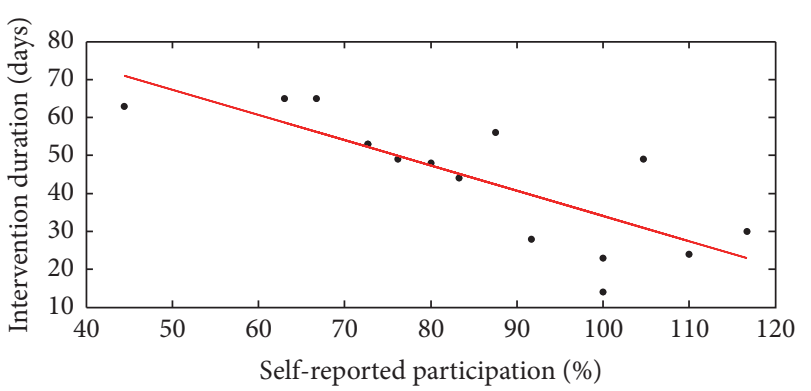

- Observed

- Linear

Figure 2: Correlation of duration of the intervention to selfreported participation.

questions more slowly than usual $(n=11)$. The PCSI score went from a total of $36.9 \pm 23.2$ points before the intervention to $4.3 \pm 5.0$ points after the intervention $(Z=-3.18, p=$ 0.001 ). The self-reported abnormality score (PSCI item 21) decreased significantly from $2.0 \pm 3.3$ points to $0.2 \pm 0.4$ points $(Z=-2.88, p=0.004)$. Parents reported similar decrease in symptom perception of the PCSI score from $38.8 \pm 20.3$ to $12.8 \pm 9.6$ points $(Z=-2.904, p=0.004)$. They reported an abnormality score (item 21) of $2.1 \pm 0.7$ and $0.6 \pm 0.5$ points before and after the intervention, respectively $(Z=$ $-2.879, p=0.004)$. Abnormality scores were similar between participants and their parents $(Z=-1.342, p=0.180)$.

3.4. Neuropsychological Results. The results of the neuropsychological test assessment are summarized in Table 3. Participants showed better performance in verbal episodic memory, both in total learning $(Z=-2.843, p=0.004)$ and in immediate recall $(Z=-2.68, p=0.001)$, in switching semantic verbal fluency $(Z=-2.147, p=0.032)$ and working memory (operational component (backward)) $(Z=-2.54$, $p=0.011)$ and they made less omission type errors in a task measuring different attention processes $(Z=-2.386$, $p=0.017)$ after the Active Rehabilitation Intervention. Other neuropsychological subtests did not differ when compared to the initial evaluation. No correlations were found between the Active Rehabilitation Intervention duration and the parental anxiety measured by the STAI for state anxiety $(r=0.112$, $p=0.692)$ and trait anxiety $(r=0.042, p=0.881)$.

3.5. Coordination and Balance. Coordination and balance results are presented in Table 4. Modified Balance Error Scoring System (BESS) on one leg $(Z=-3.068, p=0.002)$ and tandem $(Z=-2.149, p=0.032)$ stances, tandem gait $(Z=-3.233, p=0.001)$, and the Finger-to-nose $(Z=$
-3.234, $p=0.001)$ scores improved after the intervention. Modified Clinical Test of Sensory Interaction on Balance (mCTSIB) under the conditions: Eyes opened, firm surface $(Z=$ -2.217, $p=0.027)$, Eyes opened, foam surface $(Z=-2.309$, $p=0.021)$ and Eyes closed, foam surface $(Z=-3.068, p=$ 0.002 ) were significantly improved. Limit of Stability (LOS) improved from $56.6 \pm 13.1 \%$ to $70.8 \pm 9.9 \%(Z=-3.068, p=$ $0.002)$. Finally, the BOT-2 subtests of bilateral coordination $(Z=-2.673, p=0.008)$ and upper-limb coordination $(Z=-3.121, p=0.002)$ improved significantly after the intervention while the balance subtest remained unchanged $(Z=-0.841, p=0.400)$.

\section{Discussion}

The present study investigated the effects of an Active Rehabilitation Intervention integrated with standard care [1] on recovery, assessed by a postconcussion symptom inventory, cognitive function, and coordination and balance performance in a slow-to-recover paediatric population following a mTBI. All participants reported full recovery. The duration of the intervention was correlated with selfreported participation. The majority of coordination and balance assessment tests presented a significant improvement following the intervention.

Since postconcussion symptoms are not specific to mTBI, some patients may report symptoms on PCSI even if they report having recovered from their mTBI [42]. In this study, participant's self-reported abnormality score normalized after the Active Rehabilitation Intervention. Although there is a need to develop accessible and valid interventions to improve recovery in paediatric mTBI population, the literature supports the use of exercise as an Active Rehabilitation Intervention when symptoms persist beyond the expected recovery period after mTBI in adults $[25,26]$. To date, only three similar studies conducted such interventions in youth $[9,35,45]$. Our intervention was inspired by the Montréal Children's Hospital Trauma Centre Mild Traumatic Brain Injury Program $[9,45]$. Although our intervention differs in frequency of participation per week and in intensity/duration of aerobic exercise reached at the end of the program, the total duration of the Active Rehabilitation Intervention before recovery (49 \pm 17 days) was similar to those observed by others [9, 45]. The Active Rehabilitation Intervention duration was not correlated with duration of autoreported postconcussion symptoms since the last mTBI $(r=0.205$, $p=0.464)$. Considering that all participants reported a complete recovery from mTBI after the intervention, it is possible that physical activity had promoted recovery after mTBI, although recovery time overlaps this, as observed 

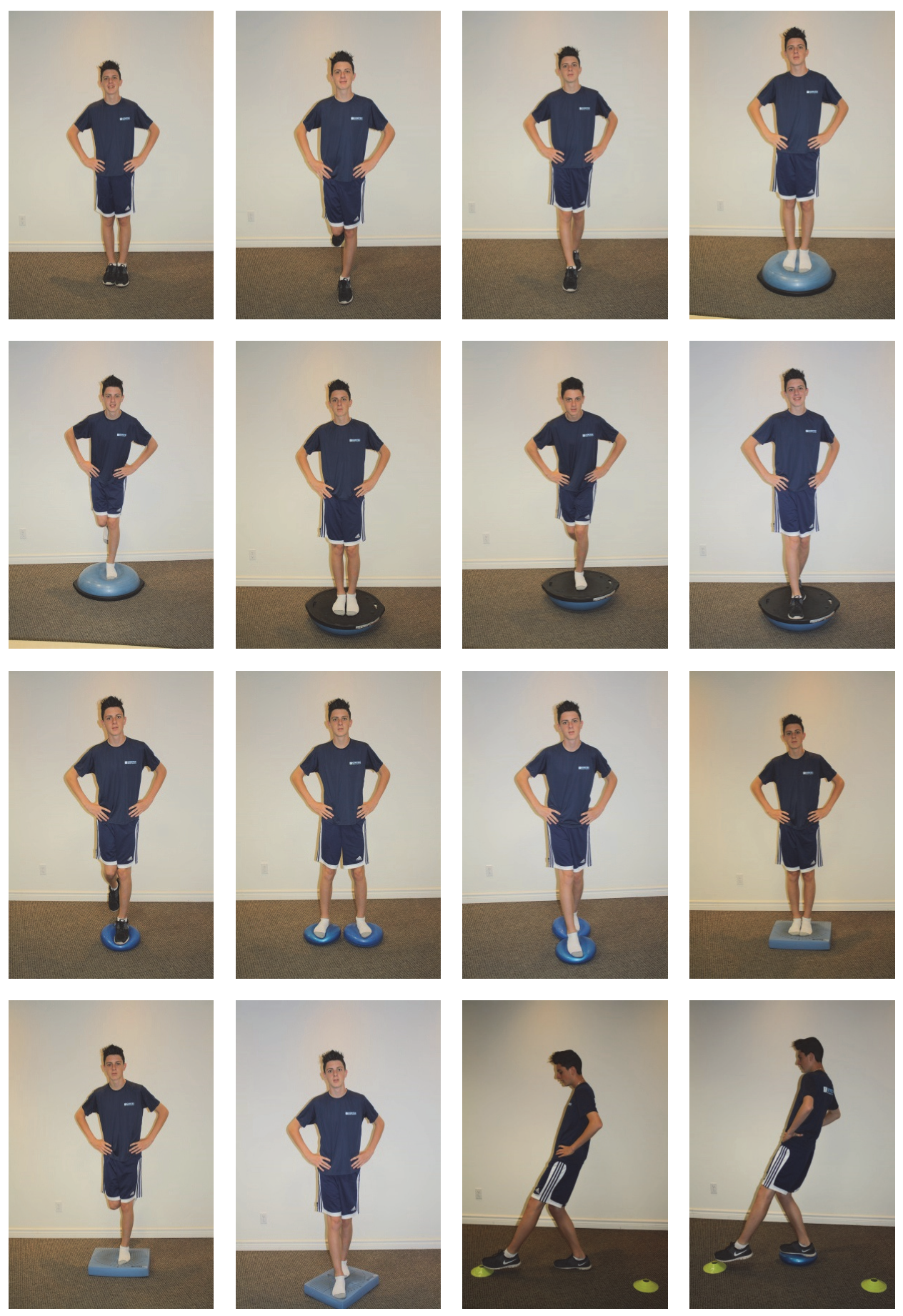

FIgURE 3: Therapeutic exercises.

by Barlow et al. [8]. Moreover, there is an apparent doseresponse relationship between duration of the intervention and self-reported participation $(r=-0.792, p \leq 0.001)$. This leaves us to believe in the effectiveness of exercise to decrease postconcussion symptoms. On the other hand, we cannot rule out the possibility of a bias created by the selfreported nature of the participation assessment.

Neuropsychological results suggest that athletes showed better performance in some verbal episodic memory, verbal fluency, working memory (operational component), and attention processes after the Active Rehabilitation Intervention. These results are consistent with the literature, indicating that episodic verbal memory, verbal fluency, working memory, and attention processes appear to be affected following a mTBI $[53,54]$. Although there is a significant improvement in some parameters of cognitive functions, other parameters were not affected by the intervention (i.e., verbal memory (ListB, Delayed), verbal fluency (phoenemic, 
TABLE 3: Neuropsychological results.

\begin{tabular}{|c|c|c|c|c|}
\hline & Before intervention & After intervention & $Z$ & $p$ \\
\hline \multicolumn{5}{|l|}{ RAVLT } \\
\hline Trials 1 to 5 total $^{*}$ & $47.46 \pm 6.18$ & $54.38 \pm 7.34$ & $-2.843^{\mathrm{b}}$ & 0.004 \\
\hline List B interference & $4.76 \pm 1.59$ & $6.23 \pm 1.36$ & $-1.736^{\mathrm{b}}$ & 0.083 \\
\hline Immediate recall $^{*}$ & $9.77 \pm 2.20$ & $11.54 \pm 1.90$ & $-2.568^{\mathrm{b}}$ & 0.001 \\
\hline Delayed recall & $10.08 \pm 2.66$ & $11.15 \pm 2.27$ & $-1.724^{\mathrm{b}}$ & 0.085 \\
\hline \multicolumn{5}{|l|}{ Verbal fluency (words) } \\
\hline Phonemic & $26.60 \pm 7.23$ & $29.60 \pm 9.43$ & $-1.449^{\mathrm{b}}$ & 0.147 \\
\hline Semantic & $37.64 \pm 4.24$ & $35.21 \pm 4.81$ & $-1.749^{c}$ & 0.080 \\
\hline Semantic switching (total responses) ${ }^{*}$ & $14.50 \pm 2.21$ & $11.93 \pm 2.62$ & $-2.147^{\mathrm{c}}$ & 0.032 \\
\hline Semantic switching (total switching) & $13.64 \pm 2.37$ & $11.36 \pm 2.41$ & $-1.891^{\mathrm{c}}$ & 0.059 \\
\hline \multicolumn{5}{|l|}{ Digit span } \\
\hline Forward & $9.14 \pm 1.70$ & $9.29 \pm 1.49$ & $-0.426^{\mathrm{b}}$ & 0.670 \\
\hline Backward* & $7.43 \pm 1.10$ & $8.64 \pm 1.91$ & $-2.537^{\mathrm{b}}$ & 0.011 \\
\hline \multicolumn{5}{|l|}{ SDMT } \\
\hline Total & $53.43 \pm 7.59$ & $56.86 \pm 9.53$ & $-1.857^{\mathrm{b}}$ & 0.063 \\
\hline \multicolumn{5}{|l|}{ CPT II } \\
\hline Omission* & $4.33 \pm 3.94$ & $1.18 \pm 1.17$ & $-2.386^{c}$ & 0.017 \\
\hline Commission & $23.92 \pm 10.08$ & $19.81 \pm 7.08$ & $-1.532^{c}$ & 0.126 \\
\hline Hit & $380.80 \pm 56.99$ & $369.48 \pm 35.67$ & $-0.533^{\mathrm{c}}$ & 0.594 \\
\hline Hit reaction time & $6.10 \pm 2.66$ & $4.73 \pm 1.24$ & $-1.600^{\mathrm{c}}$ & 0.110 \\
\hline Variability & $10.04 \pm 7.23$ & $6.32 \pm 1.61$ & $-0.800^{\mathrm{c}}$ & 0.424 \\
\hline Detectability & $0.42 \pm 0.585$ & $0.52 \pm 0.33$ & $-1.512^{\mathrm{c}}$ & 0.130 \\
\hline
\end{tabular}

${ }^{*}$ Significant statistical difference.

Note: RAVLT, Rey auditory verbal learning test; SDMT, symbol-digit modalities test; CPT, Continuous Performance Task.

${ }^{\mathrm{b}}$ Based on negative ranks.

${ }^{c}$ Based on positive ranks.

TABLE 4: Coordination and balance.

\begin{tabular}{|c|c|c|c|c|}
\hline & Beforeintervention & After intervention & $Z$ & $p$ \\
\hline \multicolumn{5}{|l|}{ SCAT3 } \\
\hline BESS double leg stance & $0.07 \pm 0.26$ & $0.00 \pm 0.00$ & $-1.000^{\mathrm{b}}$ & 0.317 \\
\hline BESS one leg stance* & $5.20 \pm 2.96$ & $1.73 \pm 2.63$ & $-3.068^{\mathrm{b}}$ & 0.002 \\
\hline BESS tandem stance* & $2.80 \pm 2.48$ & $1.20 \pm 2.01$ & $-2.149^{\mathrm{b}}$ & 0.032 \\
\hline Tandem gait ${ }^{*}$ & $17.93 \pm 7.89$ & $13.21 \pm 4.08$ & $-3.233^{\mathrm{b}}$ & 0.001 \\
\hline Finger-to-nose ${ }^{*}$ & $3.54 \pm 0.55$ & $3.00 \pm 0.48$ & $-3.234^{\mathrm{b}}$ & 0.001 \\
\hline \multicolumn{5}{|l|}{ Biosway } \\
\hline mCTSIB eyes opened firm surface* & $0.53 \pm 0.27$ & $0.39 \pm 0.17$ & $-2.217^{\mathrm{b}}$ & 0.027 \\
\hline mCTSIB eyes closed firm surface & $1.12 \pm 0.88$ & $0.69 \pm 0.21$ & $-1.874^{\mathrm{b}}$ & 0.061 \\
\hline mCTSIB eyes opened foam surface* & $0.78 \pm 0.21$ & $0.67 \pm 0.19$ & $-2.309^{\mathrm{b}}$ & 0.021 \\
\hline mCTSIB eyes closed foam surface* & $2.27 \pm 0.60$ & $1.87 \pm 0.46$ & $-1.960^{\mathrm{b}}$ & 0.050 \\
\hline LOS $^{*}$ & $56.6 \pm 13.14$ & $70.8 \pm 9.92$ & $-3.068^{\mathrm{c}}$ & 0.002 \\
\hline \multicolumn{5}{|l|}{ BOT2 } \\
\hline Bilateral coordination* & $12.33 \pm 4.69$ & $16.07 \pm 4.03$ & $-2.673^{c}$ & 0.008 \\
\hline Balance & $12.07 \pm 4.82$ & $13.27 \pm 4.43$ & $-0.841^{\mathrm{c}}$ & 0.400 \\
\hline Upper-limb coordination $^{*}$ & $13.73 \pm 4.08$ & $18.33 \pm 4.03$ & $-3.121^{\mathrm{c}}$ & 0.002 \\
\hline
\end{tabular}

${ }^{*}$ Significant statistical difference.

${ }^{\mathrm{b}}$ Based on positive ranks.

${ }^{\mathrm{c}}$ Based on negative ranks. 
semantic, semantic switching), working memory (forward), information processing, and attention processing (commission, hit, Hit reaction time, variability, and detectability)). This finding may be explained by the fact that athletes initially did not show any cognitive impairment. It may also relate to an incomplete recovery process, although participants report a subjective improvement in terms of number and intensity of autoreported symptoms. This is consistent with the literature indicating that although, in most cases, cognitive recovery largely overlaps with the time course of symptom recovery, it may occasionally follow clinical symptom resolution [1, $59,60]$. However, the limitations of the study, including the use of a small sample size and the use of alternative forms of neuropsychological tests, which could have induced a learning effect on the posttest measures, may have reduced the scope of this study. Participants demonstrated a significant improvement in coordination and balance following the intervention. These results are consistent with the literature indicating that coordination and balance are known to be altered after a mTBI in youth and young adults [53, 6164]. The coordination and balance components of the Active Rehabilitation Intervention could impact the coordination and balance assessment results under the effect of practice. Therefore, the interpretation of the results must be made cautiously.

The lack of a control group and the limited number of participants do not allow us to draw conclusions about the effectiveness of this intervention. However, it is likely that maintaining physical rest is not optimal when the recovery process is longer than expected in youth. No participant reported having a deterioration of their condition following the Active Rehabilitation Intervention. Therefore, it is likely that the initiation of progressive low- to high-intensity physical activity, without risk of fall or impact, is safe in young athletes one month following mTBI. Physiotherapy treatments may also have had an impact on physical postconcussive symptoms.

\section{Conclusion}

A progressive submaximal Active Rehabilitation Intervention may be an important asset in the recovery in young patients who are slow-to-recover following a mTBI. The majority of coordination and balance assessment tests and some cognitive functions, such as working memory, verbal memory, verbal fluency, and attention processes, presented a significant improvement following the Active Rehabilitation Intervention. Symptoms resolved in every participant independently of the onset of the Active Rehabilitation Intervention in the recovery process. It is unclear how the Active Rehabilitation Intervention has influenced these results. This study is a step toward the integration of a multimodal rehabilitation intervention in patients who are slow-to-recover after a mTBI. Further studies including more participants and a control group are needed to validate this promising new approach. This study has the potential to influence traumatology practice and may promote sports therapy in mTBI rehabilitation, although additional research in this area is needed.

\section{Competing Interests}

The authors declare that there is no conflict of interests regarding the publication of this manuscript.

\section{Acknowledgments}

The authors' sincere thanks are due to the health care professionals from Cortex Médecine et Réadaptation Concussion Clinic who supported this research. This project was held in a Canadian collective effort to improve the care of children and adolescents with mTBI in collaboration with the paediatric mTBI Rehabilitation Intervention Study. This study was funded by Fonds de recherche du Québec-Santé (FRQ-S) and the Corporation des Thérapeutes du Sport du Québec research grant.

\section{References}

[1] P. McCrory, W. Meeuwisse, M. Aubry et al., "Consensus statement on concussion in sport-the 4 th International conference on concussion in sport held in Zurich, November 2012," Clinical Journal of Sport Medicine, vol. 23, no. 2, pp. 89-117, 2013.

[2] Canadian Institute for Health Information, Head injuries in Canada: A Decade of Change (1994-1995 to 2003-2004), 2006, http://www.cihi.ca/.

[3] J. L. Guerrero, D. J. Thurman, and J. E. Sniezek, "Emergency department visits associated with traumatic brain injury: United States, 1995-1996," Brain Injury, vol. 14, no. 2, pp. 181-186, 2000.

[4] A. W. Selassie, D. A. Wilson, E. E. Pickelsimer, D. C. Voronca, N. R. Williams, and J. C. Edwards, "Incidence of sport-related traumatic brain injury and risk factors of severity: A PopulationBased Epidemiologic Study," Annals of Epidemiology, vol. 23, no. 12, pp. 750-756, 2013.

[5] D. J. Thurman, "The epidemiology of traumatic brain injury in children and youths: a review of research since 1990," Journal of Child Neurology, vol. 31, no. 1, pp. 20-27, 2016.

[6] J. D. Cassidy, L. J. Carroll, P. M. Peloso et al., "Incidence, risk factors and prevention of mild traumatic brain injury: results of the WHO Collaborating Centre Task Force on Mild Traumatic Brain Injury," Journal of Rehabilitation Medicine, vol. 43, pp. 28 60, 2004.

[7] W. H. A. Ryu, A. Feinstein, A. Colantonio, D. L. Streiner, and D. R. Dawson, "Early identification and incidence of mild TBI in Ontario," Canadian Journal of Neurological Sciences, vol. 36, no. 4, pp. 429-435, 2009.

[8] K. M. Barlow, S. Crawford, A. Stevenson, S. S. Sandhu, F. Belanger, and D. Dewey, "Epidemiology of postconcussion syndrome in pediatric mild traumatic brain injury," Pediatrics, vol. 126, no. 2, pp. e374-e381, 2010.

[9] I. Gagnon, C. Galli, D. Friedman, L. Grilli, and G. L. Iverson, "Active rehabilitation for children who are slow to recover following sport-related concussion," Brain Injury, vol. 23, no. 12, pp. 956-964, 2009.

[10] J. Ponsford, C. Willmott, A. Rothwell et al., "Cognitive and behavioral outcome following mild traumatic head injury in children," Journal of Head Trauma Rehabilitation, vol. 14, no. 4, pp. 360-372, 1999.

[11] R. Zemek, N. Barrowman, S. B. Freedman et al., "Clinical risk score for persistent postconcussion symptoms among children 
with acute concussion in the ED," The Journal of the American Medical Association, vol. 315, no. 10, pp. 1014-1025, 2016.

[12] C. C. Giza, J. S. Kutcher, S. Ashwal et al., "Summary of evidence-based guideline update: evaluation and management of concussion in sports: report of the Guideline Development Subcommittee of the American Academy of Neurology," Neurology, vol. 80, no. 24, pp. 2250-2257, 2013.

[13] M. E. Halstead and K. D. Walter, "American Academy of Pediatrics. Clinical report-sport-related concussion in children and adolescents," Pediatrics, vol. 126, no. 3, pp. 597-615, 2010.

[14] Ontario Neurotrauma Fondation, Guidelines for Concussion/ mTBI and Persistant Symptoms, 2nd edition, 2013.

[15] R. Zemek, S. Duval, and C. Dematteo, Guideline for Diagnosing and Managing Pediatric Concussion, Neurotrauma Foundation, Ontario, Canada, 1st edition, 2014.

[16] W. E. Amonette and K. A. Mossberg, "Ventilatory anaerobic thresholds of individuals recovering from traumatic brain injury compared with noninjured controls," Journal of Head Trauma Rehabilitation, vol. 28, no. 5, pp. E13-E20, 2013.

[17] J. G. Baker, M. S. Freitas, J. J. Leddy, K. F. Kozlowski, and B. S. Willer, "Return to full functioning after graded exercise assessment and progressive exercise treatment of postconcussion syndrome," Rehabilitation Research and Practice, vol. 2012, Article ID 705309, 7 pages, 2012.

[18] M. Clausen, D. R. Pendergast, B. Willer, and J. Leddy, “Cerebral blood flow during treadmill exercise is a marker of physiological postconcussion syndrome in female athletes," The Journal of Head Trauma Rehabilitation, vol. 31, no. 3, pp. 215-224, 2016.

[19] R. L. Conder and A. A. Conder, "Heart rate variability interventions for concussion and rehabilitation," Frontiers in Psychology, vol. 5, article 890, 2014.

[20] J. Leddy, A. Hinds, D. Sirica, and B. Willer, "The role of controlled exercise in concussion management," $P M \diamond R$, vol. 8 , no. 3, supplement, pp. S91-S100, 2016.

[21] J. J. Leddy, J. G. Baker, and B. Willer, "Active rehabilitation of concussion and post-concussion syndrome," Physical Medicine \& Rehabilitation Clinics of North America, vol. 27, no. 2, pp. 437454, 2016.

[22] J. J. Leddy, K. Kozlowski, J. P. Donnelly, D. R. Pendergast, L. H. Epstein, and B. Willer, "A preliminary study of subsymptom threshold exercise training for refractory post-concussion syndrome," Clinical Journal of Sport Medicine, vol. 20, no. 1, pp. 21$27,2010$.

[23] J. J. Leddy, K. Kozlowski, M. Fung, D. R. Pendergast, and B. Willer, "Regulatory and autoregulatory physiological dysfunction as a primary characteristic of post concussion syndrome: implications for treatment," NeuroRehabilitation, vol. 22, no. 3, pp. 199-205, 2007.

[24] C. O. Tan, W. P. Meehan III, G. L. Iverson, and J. A. Taylor, "Cerebrovascular regulation, exercise, and mild traumatic brain injury," Neurology, vol. 83, no. 18, pp. 1665-1672, 2014.

[25] K. J. Schneider, G. L. Iverson, C. A. Emery, P. McCrory, S. A. Herring, and W. H. Meeuwisse, "The effects of rest and treatment following sport-related concussion: a systematic review of the literature," British Journal of Sports Medicine, vol. 47, no. 5, pp. 304-307, 2013.

[26] N. D. Silverberg and G. L. Iverson, "Is rest after concussion 'the best medicine?': recommendations for activity resumption following concussion in athletes, civilians, and military service members," Journal of Head Trauma Rehabilitation, vol. 28, no. 4, pp. 250-259, 2013.
[27] T. Archer, "Influence of physical exercise on traumatic brain injury deficits: scaffolding effect," Neurotoxicity Research, vol. 21, no. 4, pp. 418-434, 2012.

[28] T. Archer, K. Svensson, and M. Alricsson, "Physical exercise ameliorates deficits induced by traumatic brain injury," Acta Neurologica Scandinavica, vol. 125, no. 5, pp. 293-302, 2012.

[29] S. Brand, M. Gerber, J. Beck, M. Hatzinger, U. Pühse, and E. Holsboer-Trachsler, "High exercise levels are related to favorable sleep patterns and psychological functioning in adolescents: a comparison of athletes and controls," Journal of Adolescent Health, vol. 46, no. 2, pp. 133-141, 2010.

[30] C. De Matteo, K. A. Volterman, P. G. Breithaupt, E. A. Claridge, J. Adamich, and B. W. Timmons, "Exertion testing in youth with mild traumatic brain injury/concussion," Medicine and Science in Sports and Exercise, vol. 47, no. 11, pp. 2283-2290, 2015.

[31] I. Ensari, T. A. Greenlee, R. W. Motl, and S. J. Petruzzello, "Metaanalysis of acute exercise effects on state anxiety: an update of randomized controlled trials over the past 25 years," Depression and Anxiety, vol. 32, no. 8, pp. 624-634, 2015.

[32] G. S. Griesbach, F. Gomez-Pinilla, and D. A. Hovda, "The upregulation of plasticity-related proteins following TBI is disrupted with acute voluntary exercise," Brain Research, vol. 1016, no. 2, pp. 154-162, 2004.

[33] G. S. Griesbach, D. A. Hovda, R. Molteni, A. Wu, and F. GomezPinilla, "Voluntary exercise following traumatic brain injury: brain-derived neurotrophic factor upregulation and recovery of function," Neuroscience, vol. 125, no. 1, pp. 129-139, 2004.

[34] K. Hotting and B. Roder, "Beneficial effects of physical exercise on neuroplasticity and cognition," Neuroscience \& Biobehavioral Reviews, vol. 25, no. 13, pp. 00101-00102, 2013.

[35] B. G. Kurowski, J. Hugentobler, C. Quatman-Yates et al., "Aerobic exercise for adolescents with prolonged symptoms after mild traumatic brain injury: an exploratory randomized clinical trial," The Journal of Head Trauma Rehabilitation, In press.

[36] L. Larun, K. G. Brurberg, J. Odgaard-Jensen, and J. R. Price, "Exercise therapy for chronic fatigue syndrome," The Cochrane Database of Systematic Reviews, vol. 2, Article ID CD003200, 2015.

[37] J. J. Leddy, J. G. Baker, K. Kozlowski, L. Bisson, and B. Willer, "Reliability of a graded exercise test for assessing recovery from concussion," Clinical Journal of Sport Medicine, vol. 21, no. 2, pp. 89-94, 2011.

[38] C. W. Majerske, J. P. Mihalik, D. Ren et al., "Concussion in sports: postconcussive activity levels, symptoms, and neurocognitive performance," Journal of Athletic Training, vol. 43, no. 3, pp. 265-274, 2008.

[39] A. L. Rebar, R. Stanton, D. Geard, C. Short, M. J. Duncan, and C. Vandelanotte, "A meta-meta-analysis of the effect of physical activity on depression and anxiety in non-clinical adult populations," Health Psychology Review, vol. 9, no. 3, pp. 366378, 2015.

[40] C. D. Rethorst, B. M. Wipfli, and D. M. Landers, "The antidepressive effects of exercise: a meta-analysis of randomized trials," Sports Medicine, vol. 39, no. 6, pp. 491-511, 2009.

[41] J. Rimer, K. Dwan, D. A. Lawlor et al., "Exercise for depression," The Cochrane Database of Systematic Reviews, vol. 7, Article ID CD004366, 2012.

[42] M. D. Sady, C. G. Vaughan, and G. A. Gioia, "Psychometric characteristics of the postconcussion symptom inventory in children and adolescents," Archives of Clinical Neuropsychology, vol. 29, no. 4, pp. 348-363, 2014. 
[43] L. M. Chin, L. Chan, J. G. Woolstenhulme, E. J. Christensen, C. N. Shenouda, and R. E. Keyser, "Improved cardiorespiratory fitness with aerobic exercise training in individuals with traumatic brain injury," The Journal of Head Trauma Rehabilitation, vol. 30, no. 6, pp. 382-390, 2015.

[44] J. J. Leddy, J. L. Cox, J. G. Baker et al., "Exercise treatment for postconcussion syndrome: a pilot study of changes in functional magnetic resonance imaging activation, physiology, and symptoms," Journal of Head Trauma Rehabilitation, vol. 28, no. 4, pp. 241-249, 2013.

[45] I. Gagnon, L. Grilli, D. Friedman, and G. L. Iverson, "A pilot study of active rehabilitation for adolescents who are slow to recover from sport-related concussion," Scandinavian Journal of Medicine and Science in Sports, vol. 26, no. 3, pp. 299-306, 2016.

[46] G. A. V. Borg, "Psychophysical bases of perceived exertion," Medicine and Science in Sports and Exercise, vol. 14, no. 5, pp. 377-381, 1982.

[47] M. Schmidt, Rey Auditory Verbal Learning Test, Western Psycho-logical Services, Los Angeles, Calif, USA, 1996.

[48] D. C. Delis, E. Kaplan, and J. H. Kramer, Kaplan Executive Function System (D-KEFS), Psychological Corporation, 2001.

[49] D. Wechsler, Wechsler Adult Intelligence Scale, NCS Pearson, San Antonio, Tex, USA, 4th edition, 2008.

[50] D. Wechsler, Wechsler Intelligence Scale for Children-WISC-IV, Pychological Corporation, 2003.

[51] A. Smith, Symbol Digit Modalities Test (SDMT) Manual, Western Psychological Services, Los Angeles, Calif, USA, 1982.

[52] C. K. Conners and M. H. S. Staff, Conners' Continuous Performance Test II (CPT II V. 5), Multi-Health Systems, North Tonawanda, NY, USA, 2000.

[53] K. M. Guskiewicz, S. E. Ross, and S. W. Marshall, "Postural stability and neuropsychological deficits after concussion in collegiate athletes," Journal of Athletic Training, vol. 36, no. 3, pp. 263-273, 2001.

[54] A. Lundin, C. de Boussard, G. Edman, and J. Borg, "Symptoms and disability until 3 months after mild TBI," Brain Injury, vol. 20, no. 8, pp. 799-806, 2006.

[55] C. D. Spielberger, "State-Trait Anxiety Inventory," Corsini Encyclopedia of Psychology. 1, 2010.

[56] H. Cohen, C. A. Blatchly, and L. L. Gombash, "A study of the clinical test of sensory interaction and balance," Physical Therapy, vol. 73, no. 6, pp. 346-354, 1993.

[57] M. L. Pickerill and R. A. Harter, "Validity and reliability of limits-of-stability testing: a comparison of 2 postural stability evaluation devices," Journal of Athletic Training, vol. 46, no. 6, pp. 600-606, 2011

[58] R. Bruininks and B. Bruininks, Bruininks-Oseretsky Test of Motor Proficiency, NCS Pearson, Minneapolis, Minn, USA, 2nd edition, 2005.

[59] J. Bleiberg, A. N. Cernich, K. Cameron et al., "Duration of cognitive impairment after sports concussion," Neurosurgery, vol. 54, no. 5, pp. 1073-1080, 2004.

[60] P. Fait, B. J. McFadyen, B. Swaine, and J. F. Cantin, "Alterations to locomotor navigation in a complex environment at 7 and 30 days following a concussion in an elite athlete," Brain Injury, vol. 23, no. 4, pp. 362-369, 2009.

[61] K. M. Guskiewicz, "Assessment of postural stability following sport-related concussion.," Current Sports Medicine Reports, vol. 2, no. 1, pp. 24-30, 2003.

[62] K. M. Guskiewicz and J. K. Register-Mihalik, "Postconcussive impairment differences across a multifaceted concussion assessment protocol," $P M \mho R$, vol. 3, no. 10, supplement 2, pp. S445-S451, 2011.

[63] L. A. King, F. B. Horak, M. Mancini et al., "Instrumenting the balance error scoring system for use with patients reporting persistent balance problems after mild traumatic brain injury," Archives of Physical Medicine and Rehabilitation, vol. 95, no. 2, pp. 353-359, 2014.

[64] A. G. Schneiders, S. J. Sullivan, A. R. Gray, G. D. HammondTooke, and P. R. McCrory, "Normative values for three clinical measures of motor performance used in the neurological assessment of sports concussion," Journal of Science and Medicine in Sport, vol. 13, no. 2, pp. 196-201, 2010. 


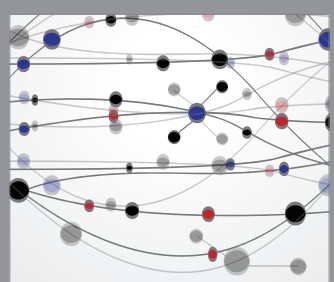

The Scientific World Journal
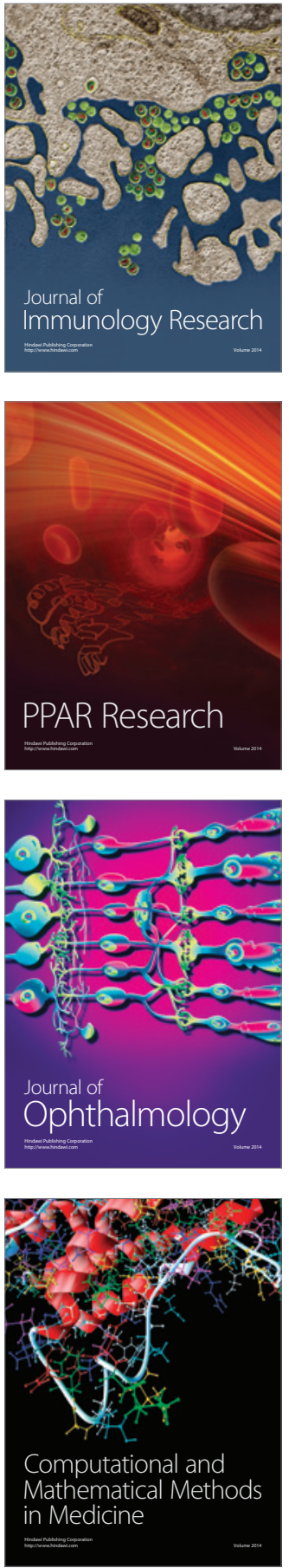

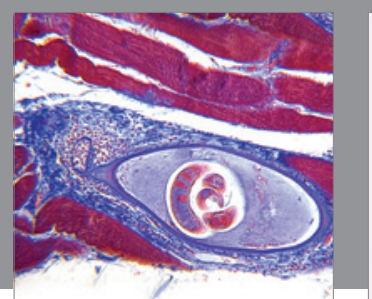

Gastroenterology Research and Practice

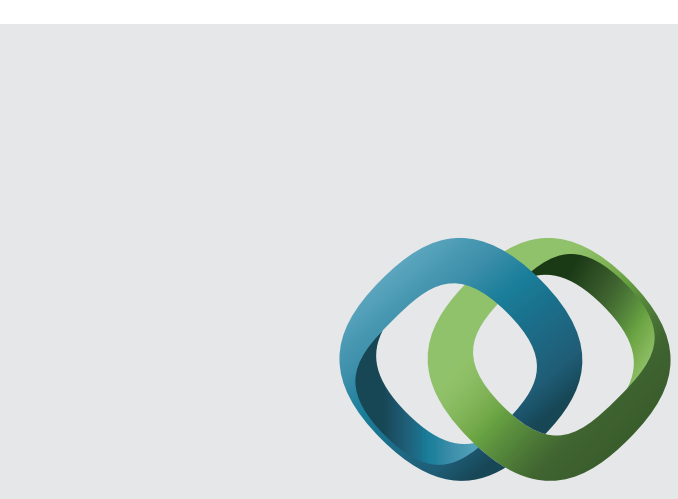

\section{Hindawi}

Submit your manuscripts at

http://www.hindawi.com
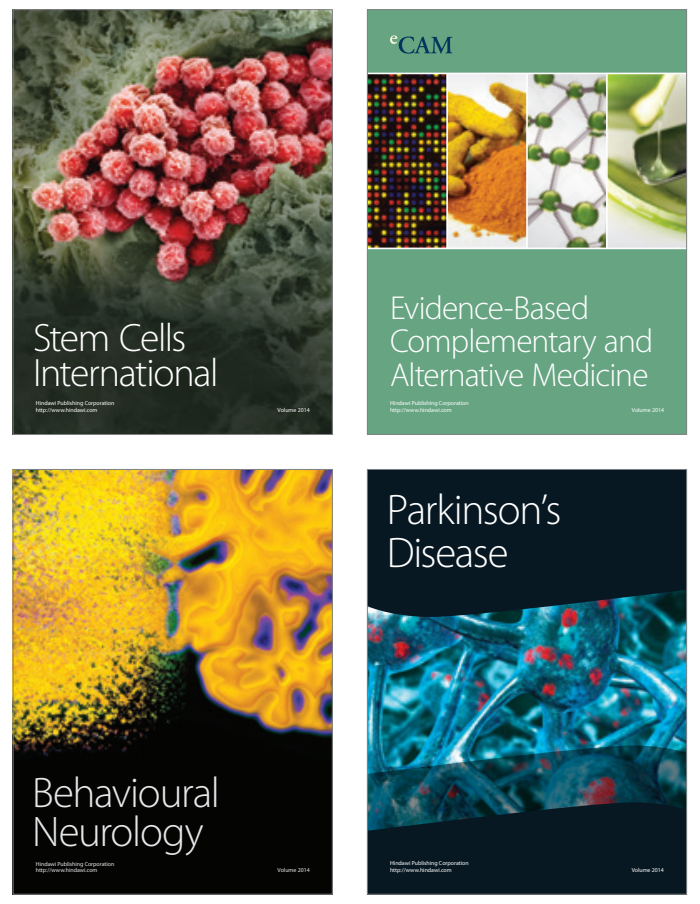
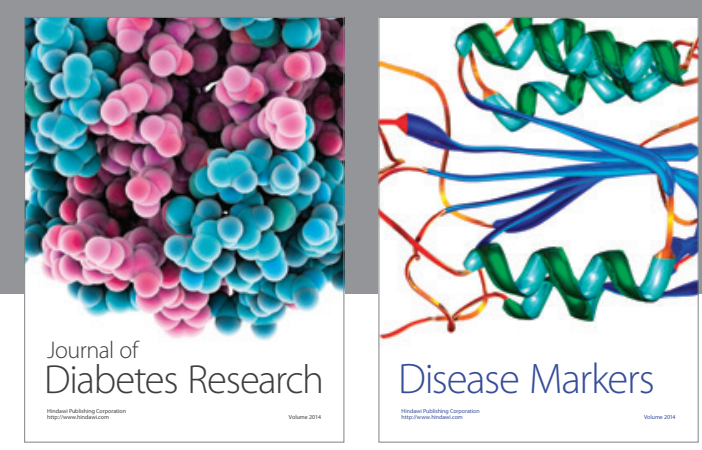

Disease Markers
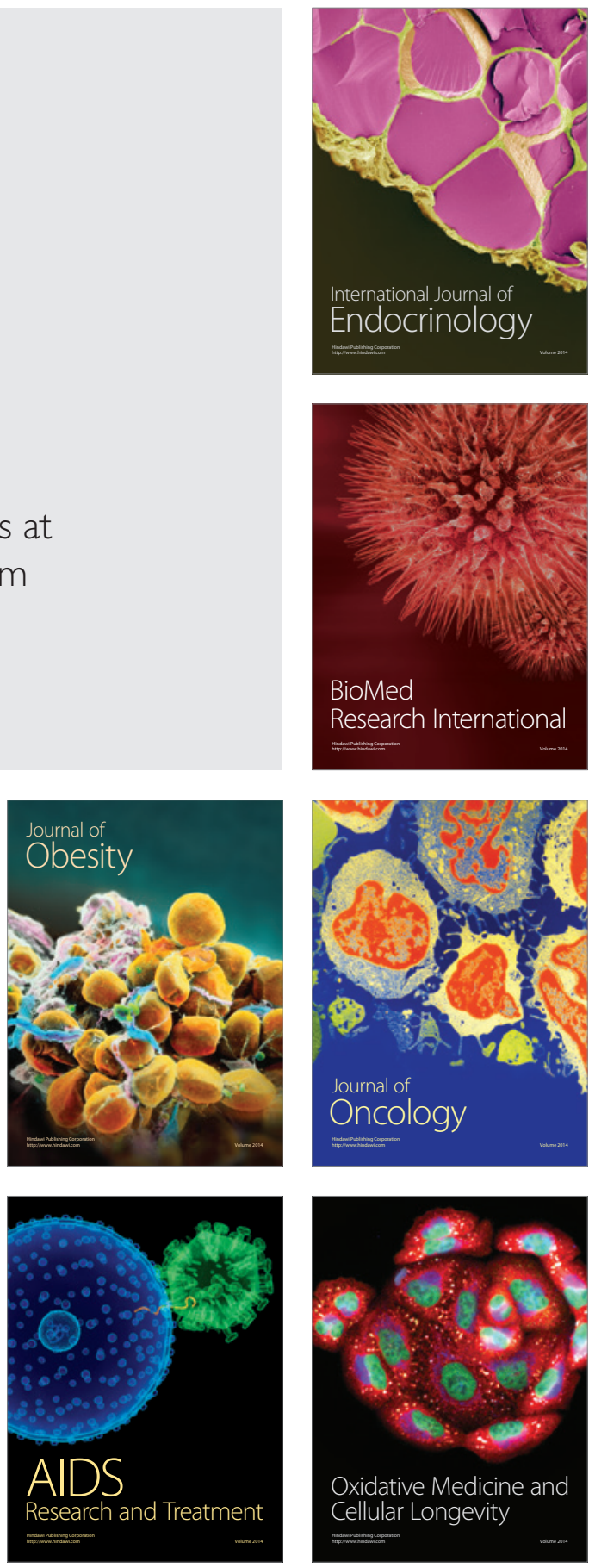